\title{
Implementasi Penggunaan Ergonomic Body Protector Serabut Kelapa Terhadap Efek Pengedara Motor
}

\author{
Iftitah Ruwana $^{1, *}$, Dayal Gustopo ${ }^{2}$, dan Anang Subardi ${ }^{3}$ \\ ${ }^{1,2}$ Program Studi Teknik Industri, Fakultas Teknologi Industri, Institut Teknologi Nasional Malang \\ ${ }^{3}$ Program Studi Teknik Mesin, Fakultas Teknologi Industri, Institut Teknologi Nasional Malang \\ *Email: ita_ruwana@yahoo.com
}

\begin{abstract}
Abstrak
Pada saat ini pengendara kendaraan bermotor sebagaian mengabaikan safety equipment dan pemakaian pelindung atau body protector sangat minim disaat berkendaraan. Produk pelindung sebenarnya sudah banyak tersedia dipasaran, namun harganya mahal, desain kurang ergonomis, bahan terbuat dari serat sintetis sehingga tidak ramah lingkungan. Fungsi protector yang kurang kuat dan kurang nyaman saat dipakai sehingga pengguna motor lebih sering memakai jaket biasa saat berkendara. Berdasarkan masalah tersebut pengunaan produk ergonomic body protector serabut kelapa dapat mempengerahui pengendara motor secara fisik dan dapat memberikan kenyamanan pada saat berkendaraan. Karakteristik fisik serabut kelapa yaitu mempunyai kekuatan tarik, elastisitas, biodegradable, dan insulasi yang baik terhadap suhu. Ergonomi body protector serabut kelapa meliputi kualitas bahan dan disain produk yang sesuai kebutuhan pengendara motor. Kualitas produk protector meliputi mouisture kekuatan tarik, impac dan kekerasan. Rancangan disain produk dilakukan dengan pengukuruan antropometri pada orang dewasa. Penggunaan ergonomic body protector mempunyai efek terhadap pengendara motor yaitu dengan memberikan rasa hangat dan kenyamanan pada pengendara motor.
\end{abstract}

Kata Kunci: Ergonomis Body Protector, Efek Pengendara, Serabut Kelapa

\section{Pendahuluan}

Manusia dalam kehidupannya banyak menggunakan desain sebagai fasilitas penunjang aktivitasnya. Manusia menginginkan desain sebagai produk yang sesuai dengan trend dan memenuhi kebutuhan yang semakin meningkat. Melihat kondisi saat ini, kecenderungan desain yang berubah akibat peningkatan kebutuhan manusia menimbulkan kesadaran manusia pentingnya desain yang baik dan representative. Desain mencakup masalah yang berhubungan dengan sarana kebutuhan manusia.

Ergonomi membentuk kondisi yang efektif, aman, sehat, nyaman dan efisien (EASNE). Ergonomi tidak terbatas hanya pada rancangan, melainkan jauh lebih luas, yakni merancang metode, alat dan sistem kerja yang sesuai dengan manusianya atau dikenal dengan istilah Human Centered Design. Protective clothing apabila tidak sesuai dengan kenyamanan dan kebebasan pada saat bergerak, akan berdampak dan memiliki efek negatif. Faktor yang menentukan kenyamanan clothing protective yaitu desain dan pertimbangan kenyamanan penggunaan [1].

Serabut kelapa merupakan bagian terluar buah kelapa yang membungkus tempurung kelapa. Ketebalan sabut kelapa berkisar 5-6 cm yang terdiri atas lapisan terluar (exocarpium) dan lapisan dalam (endocarpium). Endocarpium mengandung serat-serat halus yang dapat digunakan sebagai bahan pembuat tali, karung, pulp, karpet, sikat, keset, isolator panas dan suara, filter, bahan pengisi jok kursi/mobil dan papan hardboard. Satu butir buah kelapa menghasilkan 0,4 kg sabut yang mengandung $30 \%$ serat. Komposisi kimia sabut kelapa terdiri atas selulosa, lignin, pyroligneous acid, gas, arang, ter, tannin, dan potasium [5]. 


\section{Metodologi Penelitian}

Untuk memperoleh data yang diharapkan, peneliti mengambil data primer yakni dengan melakukan uji coba secara berulang-ulang dan bertahap. Pertama, peneliti menganalisis persoalan yang sedang terjadi pada masyarakat, sehingga peneliti memiliki alasan yang mendasri penelitian ini dan merumuskan masalah yang tertulis di pendahuluan. Kedua, mengukur antropometri dari 10 sampel penelitian. Keempat, peneliti menyiapkan alat-alat maupun bahan yang akan digunakan yakni alat pengukur tekanan darah dan alat pengukur suhu tubuh yang nantinya akan digunakan sebagai bahan kajian. Kelima, pelaksanaan iji coba, uji coba dikakukan dengan waktu yang berbeda yakni pagi dan siang. Pengujian pemakai produk body protector pemakaian disain ergonomic meliputi, kondisi tubuh (suhu tubuh), tekanan darah dan detak jantung. pemakaian pada waktu pagi dan siang Keenam, pengumpulan data dan analisa.
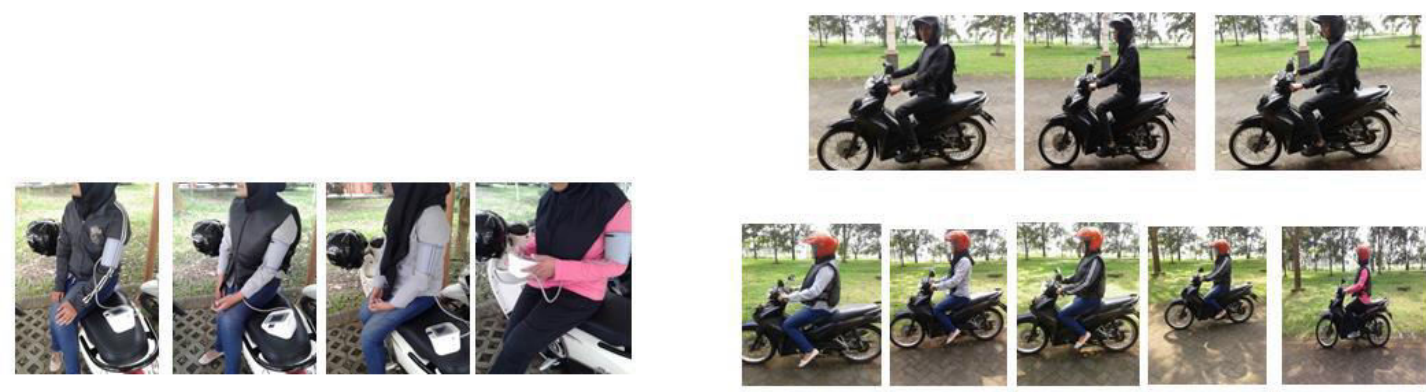

Gambar 1. Pengukuran dan Implementasi Body Protector

\section{Hasil Dan Pembahasan}

Hasil dari pengukuran telah didapat data sebagai berikut

Table 1. Data Antropometri Laki-laki

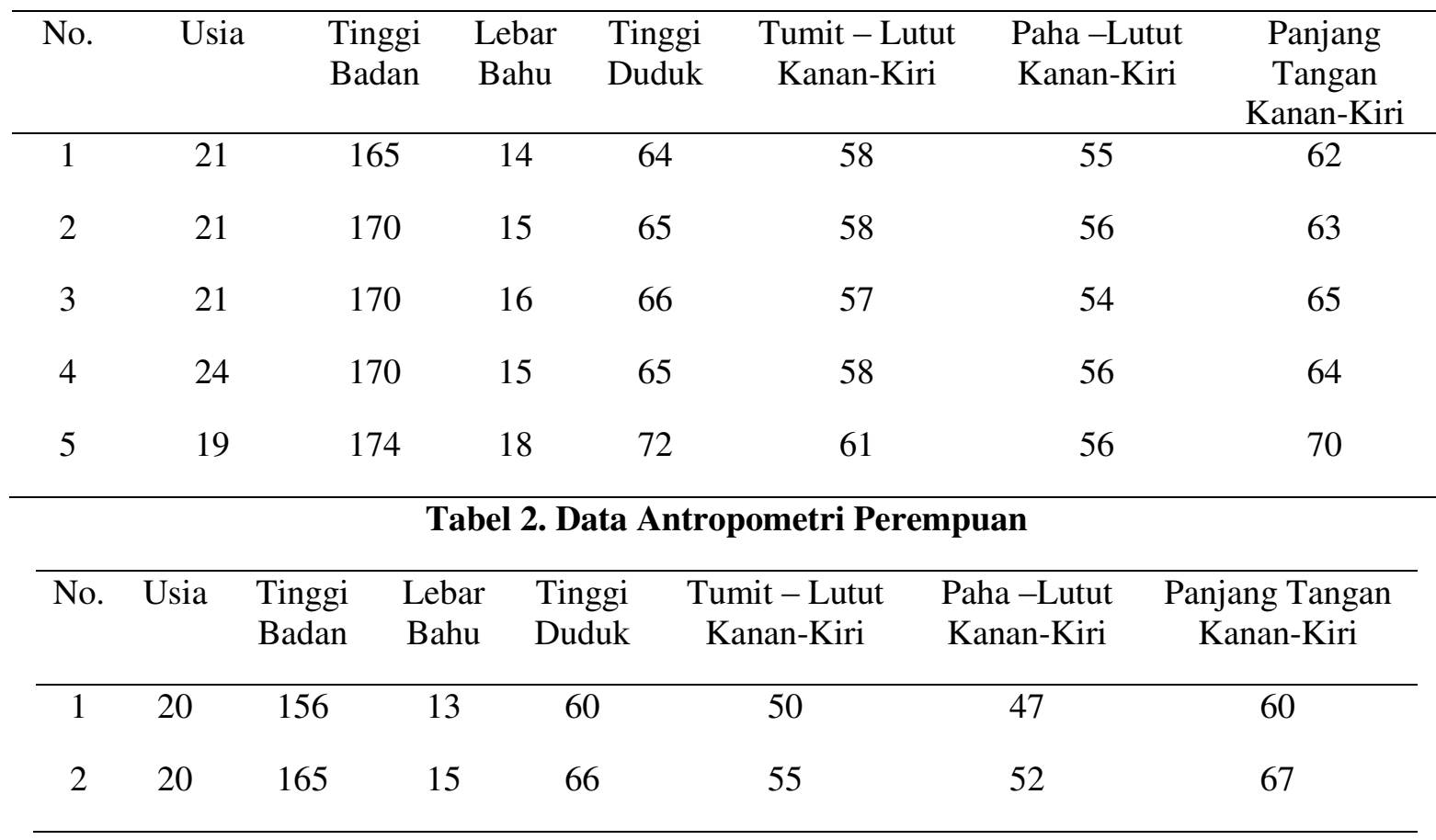




\begin{tabular}{llllllll}
\hline 3 & 21 & 158 & 13 & 60 & 51 & 49 & 61 \\
4 & 21 & 160 & 14 & 62 & 52 & 50 & 64 \\
5 & 21 & 162 & 14 & 65 & 53 & 51 & 65 \\
\hline
\end{tabular}

Tabel 3. Perlakuan Tidak Melakukan Kegiatan

\begin{tabular}{clccc}
\hline No & Jenis Kelamin & $\begin{array}{c}\text { Rata-rata Suhu } \\
\text { Tubuh }\end{array}$ & $\begin{array}{c}\text { Rata-rata Tekanan } \\
\text { Darah Sistolik }\end{array}$ & $\begin{array}{c}\text { Rata-rataTekanan } \\
\text { Darah Diastolik }\end{array}$ \\
\hline 1 & Laki-laki & 36.11 & 114.5 & 72 \\
2 & Perempuan & 36.04 & 108 & 80.4 \\
\hline
\end{tabular}

Tabel 4. Perlakuan Kegiatan Dengan Menggunakan Pakaian

\begin{tabular}{ccccc}
\hline \multirow{2}{*}{ No } & $\begin{array}{c}\text { Jenis } \\
\text { Kelamin }\end{array}$ & $\begin{array}{c}\text { Rata-rata Suhu } \\
\text { Tubuh }\end{array}$ & $\begin{array}{c}\text { Rata-rata Tekanan } \\
\text { Darah Sistolik }\end{array}$ & $\begin{array}{c}\text { Rata-rataTekanan } \\
\text { Darah Diastolik }\end{array}$ \\
\hline 1 & Laki-laki & 36.01 & 118.4 & 78.7 \\
2 & Perempuan & 36.11 & 110.2 & 80.1 \\
\hline
\end{tabular}

Tabel 5. Perlakuan Dengan Menggunakan Pakaian Dan Jaket

\begin{tabular}{ccccc}
\hline No & $\begin{array}{c}\text { Jenis } \\
\text { Kelamin }\end{array}$ & $\begin{array}{c}\text { Rata-rata Suhu } \\
\text { Tubuh }\end{array}$ & $\begin{array}{c}\text { Rata-rata Tekanan } \\
\text { Darah Sistolik }\end{array}$ & $\begin{array}{c}\text { Rata-rataTekanan Darah } \\
\text { Diastolik }\end{array}$ \\
\hline 1 & Laki-laki & 36.56 & 118.9 & 71.6 \\
2 & Perempuan & 36.42 & 105.6 & 80.3 \\
\hline
\end{tabular}

Tabel 6. Perlakuan Dengan Menggunakan Body Protector

\begin{tabular}{ccccc}
\hline No & $\begin{array}{c}\text { Jenis } \\
\text { Kelamin }\end{array}$ & $\begin{array}{c}\text { Rata-rata Suhu } \\
\text { Tubuh }\end{array}$ & $\begin{array}{c}\text { Rata-rata Tekanan } \\
\text { Darah Sistolik }\end{array}$ & $\begin{array}{c}\text { Rata-rataTekanan } \\
\text { Darah Diastolik }\end{array}$ \\
\hline 1 & Laki-laki & 36.84 & 115.9 & 68.5 \\
2 & Perempuan & 35.18 & 106.9 & 81.1 \\
\hline
\end{tabular}

\section{Analisis SWAT}

Analisis terhadap beban kerja yang dirasakan oleh pengendara bermotor dapat kita lihat dari analisi data menggunakan SWAT

Tabel 7. Perbandingan SWAT Rescaled Pada Laki-laki

\begin{tabular}{ccc}
\hline No & SWAT Rescaled Sebelum & SWAT Rescaled Sesudah \\
\hline 1 & 57.16 & 39.06 \\
2 & 38.38 & 24.72 \\
3 & 29.38 & 20.6 \\
4 & 58.54 & 42.3 \\
5 & 48.2 & 34.6 \\
\hline
\end{tabular}


Tabel 8. Perbandingan SWAT Rescaled Pada Perempuan

\begin{tabular}{ccc}
\hline No & SWAT Rescaled Sebelum & SWAT Rescaled Sesudah \\
\hline 1 & 42.86 & 20.46 \\
2 & 46.56 & 55.56 \\
3 & 39.04 & 21.3 \\
4 & 50.9 & 41.1 \\
5 & 34.6 & 40.8 \\
\hline
\end{tabular}

\section{Kesimpulan}

1. Dengan mengunakan boyprotector mengalami perubahan pada suhu dan rata rata tekanan darah sistolik dan diastolic pada pengendara sepeda motor laki laki dan perempuan

2. Dengan mengunakan boyprotector mengalami perubahan nilai swat rescaled pada pengendara laki laki dan perempuan

\section{Saran}

Dari hasil penelitian body protector maka masih perlu dilakukan penelitian lebih lanjut tentang efek perlakuan dari bahan dengan variasi yang lain..Dapat di aplikasi pada produk produk selain jenis produk body protector

\section{Ucapan Terima kasih}

Ucapan terima kasih kepada DP2M Direktoral Jendral Pendidikan Tinggi Kementerian Riset Teknologi dan Pendidikan Tinggi Republik Indonesia atas pembiayaan penelitian melalui dana hibah bersaing tahun anggaran 2016 sehingga dapat terwujut artikel ini.

\section{Daftar Referensi}

[1] Dlugosch, Sabine, Hong Hu, and Allan C K Chan. 2012. Impact Protective Clothing in Sport: Areas of Application and Level of Utilization. 16(3).ore, A. 2006.

[2] Kuklane, Kalev. 2000. Ergonomics of Protective Clothing

[3] Muller,D.H., Krobjilowski, A., 2003, New Discovery in the Properties of Composite Reinforced with Natural Fibers, Journal of Industrial Textiles, vol.33, no.2, pp.111-130 Sage Publ.

[4] Ruwana I, Dayal Gustopo, 2015, Peningkatan Kualitas Serabut Kelapa dengan metode Bio Scouring pada produk body protector yang ergonomis, JITI Vol 3, No 3

[5] Wie W, Gu H. 2009, Characterisation and utilization of natural coconut fibres composites. Materials and Design; 30:2741-4. 